\title{
Employee Well-being: A Hierarchical Model and the Evaluating Framework
}

\author{
Yun XIA ${ }^{1, a}$, Shao-Hua LU ${ }^{2, b}$, Kang SHI ${ }^{2, c}$ \\ ${ }^{1}$ Human Resource Department, Wuhan University of Technology, Wuhan, China \\ ${ }^{2}$ School of Management, Wuhan University of Technology, Wuhan, China \\ axiayunn@163.com, lu_shaoua@163.com, 'skwhut@163.com
}

Keywords: employee well-being, human resource management, modeling

\begin{abstract}
We established a hierarchical employee well-being (EWB) model which scrutinized the structure of employee well-being and distinguished the concept of well-being from those of occupation gratification and job satisfaction. By establishing the model, the formation process of employee well-being is analyzed. Then, the frame of influencing factors and the evaluating system of EWB are proposed, which gives possibility to efficient EWB management.
\end{abstract}

\section{Introduction}

Well-being is considered as a kind of psychological phenomenon, which has been concerned widely. In 1972, Bhutan proposed the "Gross National Happiness(GNH) index" creatively based on its "Happiness Project". From then on, the national happiness index, like GDP index, got more and more attention gradually from both governments and public societies. In China, some local governments and social institutions proposed many well-being-related index, such as Social Harmony Index, National Happiness Index, and so on. It becomes the trend to build "harmony society" and establish "happy enterprises", which reflects the importance of well-being to individual person's living and social economy development. Under this background, employee well-being(EWB) becomes a new research field and obtains fast development in recent years.

Researches on well-being can mainly be divided into two typical categories: the subjective well-being (SWB) and psychological well-being (PWB).

SWB is based on behaviorism, and explains the concept of well-being more from individual emotion and mood "sensibility". Well-being is concerned as Happiness, and emphasizes the importance of self-evaluation and personal experience of individuals. As its representative Diener pointed out, employee well-being should include the positive emotion, negative emotion, the overall satisfaction on job, and the content on other different areas[1].

However, the PWB supporters don't think so. They consider that well-being is not just happiness, but comes more from the consistency of individuals and their real ego, or from the satisfaction of their needs on self-realization, autonomy, competence and relationships. So, well-being is indeed the comprehensive result of "rational" judgment. The representative of PWB, Carol D. Ryff, defined the well-being as the potentiality to realize perfect [2], and developed a six-dimension model of PWB, i.e, self acceptance, positive relationship with others, autonomy, environment controllability, life goals and personal growth.

Existing researches on EWB is an important subset of those of SWB, and focuses mainly on the concept, construct, source and measurement of well-beings in workplaces. Some useful results have been achieved. For example, Lin [3] divides SWB into job satisfaction, life satisfaction and political harmony; Miao [4] points out that the performance of SWB in work is mainly manifested by work satisfaction. Pan [5] proposed 10 dimensions of SWB: content, mental health, social confidence, growth and progress, the target value, self acceptance, body health, balanced mind, interpersonal adaptation, and family atmosphere. However, these studies ordinarily just considered the key elements (or content) of SWB, but didn't consider the hierarchy and relationship among these elements, not to mention the gradual formation process of well-being. 
The forming process of EWB and its influencing factors aroused interests of many scholars recently. Ke [6] finds out that job is still the most important aspect of city resident's well-being and self-realization is the most important factor of this aspect. Yu [7] points out that factors which affect EWB of Chinese joint ventures mainly include salary level, interpersonal relationship, property of work, environment of work, personal characteristics, external image of enterprise, and staff welfare of enterprise. Chen [8] believes that EWB is affected by factors from individual, work and the firm level, and the formation of EWB is affected by the traction mechanism, resistance mechanism and regulation mechanism. Chen [9] studied the relationship among the influencing factors of EWB based on the six-factor model of PWB. Deng [10] analyzed the relationship among organizational commitment, psychological ownership, total compensation and job security by constructing a system model of SWB. Xia [11] established an AHP model of the influencing factors of EWB and analyzed the EWB formation mechanism based on the studies of new-generation migrant workers.

However, mostly of these studies considered EWB as work satisfaction, and didn't distinguish well-beings of different work categories and different individual characteristics.

\section{The hierarchical structure model of EWB}

In fact, well-being is the comprehensive experience of individuals when their specific requirements are met. As an individual's requirements are hierarchically structured, well-being must have the similar structure and a gradual forming process, i.e., well-being is a complex structure which is consisted of both emotional and rational factors. Specific to employee well-being (EWB), it should be not only a kind of subjective feeling which arises during individual's work process, but also a kind of psychological phenomenon. It is the result of the long-term interaction among factors of working environment, job property and personnel characteristics. Or to say, EWB is a kind of spiritual pleasure brought to individual after the dynamic person-work matching. This spiritual pleasure is not accomplished at one stroke, but is formed gradually after a relatively long time and has obvious hierarchical structure, as shown in figure 1.

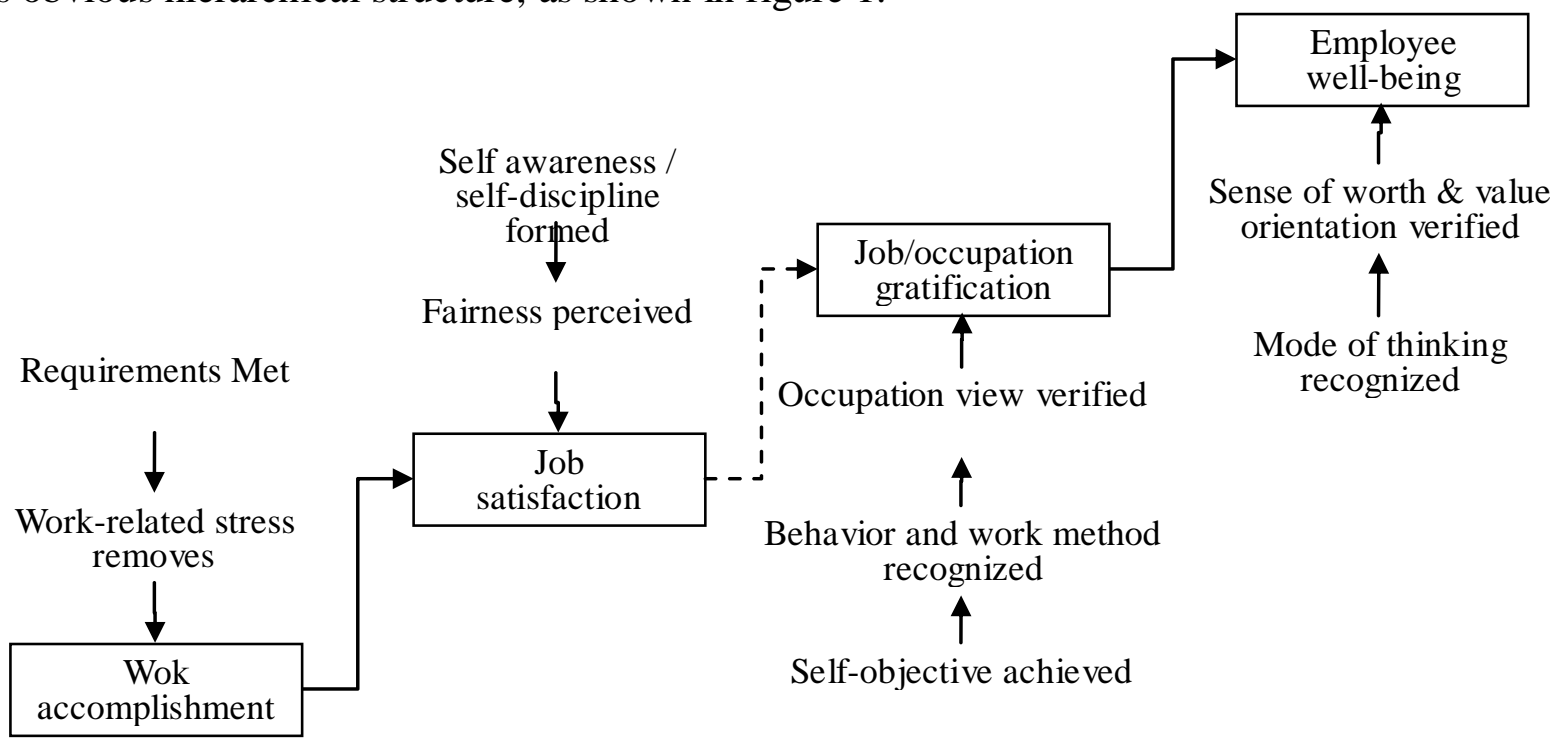

Figure 1 the hierarchical structure model of EWB

Generally, "work" is consisted of a serial of tasks which cause stresses to the individual who fulfills it. As tasks accomplished according to relative standards and norms, the task-related-stress then vanished, which brings to the individual a sense of relief. After certain amount of tasks are fulfilled and related stresses removed, the sense of relief is accumulated and gradually turns into the sense of accomplishment. The greater the stress is and the more stress removed, the stronger the accomplishment sense will be and the longer it will last. If the work is challenging enough, the 
stress eliminated will be relatively great and may exceed a certain level(i.e., the threshold), then the sense of accomplishment achieved will transform into a kind of long-term incentive. That is, the individual is proud of his/her work. However, the sense of accomplishment is largely spontaneous and of reaction level. It usually lasts a relatively short period and disappears as new "work" arrives.

While fulfilling and accomplishing works continuously, individuals develop their self awareness to their own work ability gradually, and then build some standards and requirements for themselves as to work methods, work processes, and work results. This is so-called "work principles" or "self-disciplines". When these principles or disciplines come into being, the individual's threshold for stress-resistant will ascend too. At the same time, individuals will judge whether the payment they received for work matches their work performance, taking their self awareness and work disciplines as reference. If an individual continually got appropriate payment which s/he considers matches his/her work ability and performance, s/he will think it is fair and then generate the feeling of satisfaction to his/her job. The job satisfaction grows as the individual's performance and fair payments accumulate. Job satisfaction is the balance of individual's subjective understanding and objective attributes of the job, that is, "the job is acceptable". Whether an individual satisfies his/her job depends more on his/her subjective judgment than job characteristics. For example, a lot of labor-intensive industry still attracted a large number of workers, most of whom can also work "happily" or "joyful" (but far from being "happiness" or "well-being"). Job satisfaction is not on reaction level like the sense of work accomplishment, but belongs to the level of perception.

However, satisfaction doesn't mean content. When individuals continue to accomplish given task and receive the expected payment, the feeling of being recognized will generate in their heart, and then the spontaneous enthusiasm for their work and self-confidence on their work ability grow. At this stage, individuals will set a serial of job/occupation targets for themselves intentionally or unintentionally. These targets are usually set based on their self-recognition on the occupation, the society and themselves, and compose their formal or informal occupation planning. Individuals will adjust these targets as the extent of their job satisfaction change. Usually, the more the individual's job satisfaction is, the higher his/her occupation targets will be. As these targets realize one by one, the individual will consider his work behaviors and methods are effective and his hypothesis for these behaviors and methods (i.e., his occupation view) is correct. The individual will then feel his sense of worth is realized, resulting the feeling of "fully satisfied" or "contented", which manifests as high degree of loyalty to organization and high confident on his occupation quality and working ability. That is to say, the individual is highly proud of his job/occupation, and develops job/occupation gratification, which is the result of the internal consistency of the individual and belongs to the cognitive level.

While the individual is satisfied or content with his job or occupation, he may further analyze and summarize his work behaviors and methods to develop his specific thinking mode and work methodology, which will be promoted and applied to the following work processes. If this mode or methodology works positively and is identified by the organization or others, the individual will then coordinate his subjective thought with the outsider world successfully, thus obtain the unprecedented pleasure, i.e., employee well-being(EWB), which is the highest level of individual's work-related well-being, belonging to the concept level. At this stage, the individual matches his occupation, organization, and job greatly, thus gets highly harmonious with his organization and the society.

Work accomplishment and job satisfaction are both of feeling and sentiment category, which are always triggered by external factors of individuals and may arise at any time during the work. However, job/occupation gratification and employee well-being are more about cognition and emotional level, which is a kind of long-term effect. It can hardly be aroused by one work accomplishment or accidental job satisfaction, but developed gradually while the periodical self-appraisal results consistent with the individual's expectation. So, employee well-being is the transition when individual's work accomplishment and job satisfaction accumulated to a certain extent and exceeded the threshold. Most of the existing literature did not distinguish job satisfaction 
from employee well-being, because they ignored this transition process.

It is necessary to emphasize that employee well-being is a socialized concept, and is associated with the social culture and universal value orientation. So, it is meaningless to discuss employee well-being out of the social and organization context.

\section{The influencing factors of EWB}

Employee well-being (EWB) has a hierarchical structure, as mentioned previously. So, the factors effecting EWB is also hierarchical. As to individuals on different EWB level, their incentives for higher level well-being are different, too.

According to the hierarchical model of EWB presented above, a hierarchical system of influencing factors of EWB is proposed here, as in table 1.

Table 1 Influencing factors of EWB

\begin{tabular}{|c|c|c|c|}
\hline \multirow{2}{*}{$\begin{array}{l}\text { Level of } \\
\text { EWB }\end{array}$} & \multicolumn{3}{|c|}{ Influencing factors } \\
\hline & $\begin{array}{l}\text { Internal factors of } \\
\text { individuals }\end{array}$ & $\begin{array}{l}\text { Job/occupation } \\
\text { attributes }\end{array}$ & Environmental factors \\
\hline $\begin{array}{l}\text { Employee } \\
\text { well-being }\end{array}$ & $\begin{array}{l}\text { - Personal goal } \\
\text { - value orientation }\end{array}$ & $\begin{array}{l}\text { Occupation } \\
\text { reputation } \\
\cdot \text { work-life balance }\end{array}$ & $\begin{array}{l}\text { Social norm } \\
\cdot \text { social value } \\
\text { system/orientation }\end{array}$ \\
\hline $\begin{array}{l}\text { Occupation } \\
\text { gratification }\end{array}$ & $\begin{array}{l}\cdot \text { Requirement structure } \\
\cdot \text { Experiences } \\
\cdot \text { cognition to social norm } \\
\text { perception }\end{array}$ & $\begin{array}{l}\cdot \text { Total compensation } \\
\cdot \text { work-life relationship } \\
\cdot \text { the return of work } \\
\cdot \text { work experience }\end{array}$ & $\begin{array}{l}\cdot \text { Average society income } \\
\text { - average living standard } \\
\text { - attitude of people } \\
\text { around }\end{array}$ \\
\hline $\begin{array}{c}\text { Job } \\
\text { satisfaction }\end{array}$ & $\begin{array}{l}\text { Knowledge \& ability } \\
\text { - self role perception } \\
\text { - understanding on the } \\
\text { work requirements } \\
\text { - expectation on job return }\end{array}$ & $\begin{array}{l}\text { - Turnout of the work } \\
\text { - compensation level } \\
\text { - characteristics of the } \\
\text { organization }\end{array}$ & $\begin{array}{l}\text { - Interpersonal } \\
\text { relationship } \\
\text { - enterprise image } \\
\cdot \text { social/economy } \\
\text { environment }\end{array}$ \\
\hline $\begin{array}{l}\text { Work } \\
\text { accomplish- } \\
\text { ment }\end{array}$ & $\begin{array}{l}\text { Personality traits } \\
\cdot \text { achievement motivation } \\
\text { - expectation on work } \\
\text { output }\end{array}$ & $\begin{array}{l}\cdot \text { Work challenge } \\
\cdot \text { work autonomy } \\
\cdot \text { work significance } \\
\cdot \text { work identity }\end{array}$ & $\begin{array}{l}\text { - Support from others } \\
\text { - intensity of competition } \\
\text { - others' attitude to work } \\
\text { results }\end{array}$ \\
\hline
\end{tabular}

\section{The evaluating system of EWB}

It can not be managed if it can not be measured. To monitor and manage employee well-being, it is necessary to measure and evaluate it efficiently. As employee well-being is the comprehensive feeling and perception of individuals after they comparing their subjective understanding with the objective results, we propose the evaluating system of EWB based on the hierarchical EWB model.

In general, EWB can be evaluated through 3 progressive layers: personal perception, individual emotion, and behavioral reaction. On each layer, there are different sources of influencing factors such as job attributes, individual requirements, personal working attitudes, work performance, society recognition, and so on. By evaluating or measuring the quantity and quality of these factors on each layer, the EWB structure of an individual can be figured out roughly. 


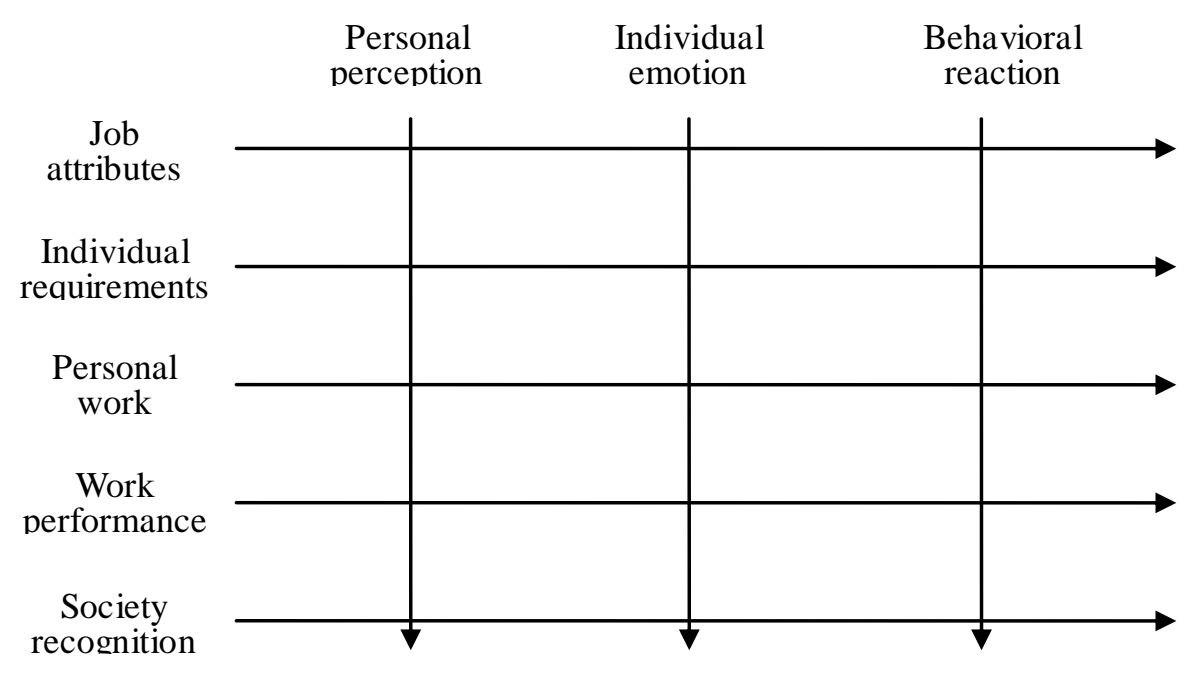

Figure 2 The measurement system of EWB

\section{Summary}

Employee well-being is the comprehensive feeling and perception of individuals after they comparing their subjective understanding with the objective results. There have been already many literature discussing employee well-being, which can be divided into two categories: subjective well-being (SWB) and psychological well-being (PWB). However, there is rarely literature which bridges these two opinions, and existing well-being-related literature usually focus mainly on performance management if they involves human resource management.

We established a hierarchical EWB model which scrutinized the structure of employee well-being and distinguished the concept of well-being from those of occupation gratification and job satisfaction. By establishing the model, the formation process of employee well-being is analyzed. Then, the frame of influencing factors and the evaluating system of EWB are proposed, which gives possibility to efficient EWB management.

\section{Acknowledgement}

This research was financially supported by "the Fundamental Research Funds for the Central Universities".

\section{References}

[1] E Diener, C Scollon, R Lucas. The evolving concept of subjective well-being: The multifaceted nature of happiness [M]. In Costa P, Siegle R (eds). Advances in cell aging and gerontology. Amsterdam: Elsevier, 2004: 187-220

[2] C Ryff, B Dinge. Best news yet on the six-factor model of well-being[J]. Social Science Research, 2006, 35(4): 1103-1119

[3] Lin Hong, Wen Tuo. An Empirical Study of National Subjective Well-being: Cases from 21 Citiesin Guangdong [J]. CONTEMPORARY FINANCE \& ECONOMICS, 2010, (5): 32-39

[4] Miao Yuanjiang, Wang Xuguang, Chen Yanfei. The Overview of the Study on Employee Well-being [J]. ENTERPRISE VITALITY, 2011, (8): 65

[5] Pan Liping. Study on the Influence of Subjective Well-being and Organizational Commitment 
on Turnover Intention Among Business Knowledge Worker [D]. Fuzhou: Fujian Normal University, 2008

[6] Ke Yan. The measurement model of subjective well-being [J]. Statistics and Decision, 2010, (21): $36-37$

[7] $\mathrm{Yu}$ Wenzhao. management psychology [M]. Dalian: Dongbei University of Finance and Economics press, 2004

[8] Chen Rongwei, Dong Furong. How to Improve Employee Work Well-Being - Based on Its Forming Mechanism [J]. ENTERPRISE VITALITY, 2012, (8): 12-14

[9] Chen Long. Study on the influencing factors and formation mechanism of employee well-being of new generation employees [D]. Wuhan: Hubei University of Technology, 2012

[10] Deng Bo, Ma Zhanjie. Systemic analysis on the formation mechanism model of employee subjective well-being [J]. Reformation \& Strategy, 2008, 24(2): 48-50

[11] Xia Jin, Wu Yanni, Xia Ji. Study on the EWB formation mechanism of new generation peasant worker[J]. Chinese Human Resource Development, 2011, (2): 34-36 